\title{
The use of industrial wastes from machine- building enterprises as packing materials for small-sized absorbers for gas emissions purification
}

\author{
Nikolay Merentsov ${ }^{1, *}$, Alexander Persidskiy ${ }^{2}$, Vitaliy Lebedev ${ }^{3}$ and Alexander \\ Golovanchikov $^{1}$ \\ ${ }^{1}$ Volgograd State Technical University, 400005 Volgograd, Russia \\ 2 JSC Federal Scientific and Production Centre «Titan - Barricady», 400071 Volgograd, Russia \\ ${ }^{3}$ Branch of LUKOIL-Engineering VolgogradNIPImorneft, 400078 Volgograd, Russia
}

\begin{abstract}
The paper covers the prospects to use industrial wastes from machine-building enterprises, appearing while machining various steel grades, as packing materials for industrial absorbers for environmental cleaning processes of gas emissions. The article provides obtained and processed in the criterial way experimental data in hydrodynamics of a packing material sample from metal working machines wastes appearing while treating Aisi 316Ti steel bars; packing material according to the classification method for processing experimental data $\lambda=f\left(R e_{m}\right)$ is oriented to the absorption process during selective gas cleaning in environmental equipment. The authors have compared the studied packing material to the packing that are widely used in industries. The authors have studied the main experimentally confirmed hydrodynamic effects indicating the high efficiency of the proposed packing material. The authors have made calculations for a small-sized industrial absorber for cleaning gas emissions with the use of the studied packing material.
\end{abstract}

\section{Introduction}

The selection of well-known and the creation of new contact packing devices for technological mass transfer equipment is always associated with the need to evaluate their effectiveness for the conditions of a particular process. Work on improving mass transfer contact devices has been very active, and this has been the subject of numerous studies by many leading scientists [1-17]. The main tasks that contact mass transfer devices are designed for are developing the inter phase surface and implementing the developed hydromechanical regimes providing mutual mixing and activation of diffusion processes between the contacting components of mass transfer processes. And all the efforts of scientists developing contact elements have been aimed precisely at imparting a certain geometry and surface properties which lead to the desired intensification effects and the

\footnotetext{
* Corresponding author: steeple@mail.ru
} 
development of hydromechanical regimes in heat and mass transfer devices [18-38]. Metal shavings obtained during the machining of various steel grades which are considered to be promising for use as a packing material have completely different configurations which depend on the physicomechanical properties of the processed materials, cutting conditions, etc. The packing elements are of a spiral structure and have fins and micro-roughness on their surface due to plastic deformations of the metal being treated after contact with the cutter. Experimental studies have shown that such geometric features of metal shavings samples (packing elements) provide the development of hydromechanical regimes and the intensification of mass transfer processes $[39,40]$. These are exactly the properties which are desired to be developed while studying new mass transfer contact devices but in this case they are generated naturally as industrial wastes appearing in large quantities at machine-building enterprises during the mechanical processing of metals by cutting. It should be mentioned that by mechanical processing of metals by cutting in optimal conditions we can obtain (produce) packing materials with the best structural and surface characteristics to meet the requirements of a specific heat and mass transfer process and device which will contribute to the highest performance of technological equipment and ensure the preservation of packing materials and resistance to heat and mass transfer products. These packing materials can undoubtedly be effectively applied in industries as packing contact devices in environmental processes for cleaning gas emissions especially in small absorption columns. The authors have focused attention precisely on processing of stainless high-alloy steel grades as they have resistance to weathering, chemical resistance, acid resistance, corrosion resistance, sufficiently high mechanical strength and, in some cases, high elasticity which depend on the composition [39-42]. One of the packing material samples will be considered in detail.

The main surface and structural features of packing materials in the form of metalworking machine wastes have been described in detail in [41, 42]. These properties give opportunities to use such packing materials for a very wide range of hydromechanical, heat and mass transfer processes and devices for various purposes.

The whole range of physicochemical and structural surface characteristics of the studied mass transfer packing in the form of metalworking machines wastes makes it especially promising for mass transfer devices of the chemical, petrochemical, metallurgical, construction, machine-building, food, pharmacological, biochemical and other industries, as well as in environmental processes of selective cleaning of liquid and gas heterogeneous systems. But the high-quality performance of such packing materials can be implemented only with competent initial classification and further structural sectional organization. And one should always be careful to use this kind of packing materials in aggressive and acidic environments, for cleaning sulfur dioxide since depending on the cutting conditions on the surface of the packing material a large number of microcracks are formed as possible source of pitting corrosion and some others. It should be noted that the surface defects which make packing materials vulnerable from the point of view of corrosion resistance can be minimized due to the optimal cutting conditions for work piece bars.

\section{Methods and materials}

The S-Aisi 316Ti packing material and the scheme of the packing cartridge equipped for experimental studies are shown in Figure 1. The main parameters of the studied S-Aisi 316Ti packing material are specific surface $400 \mathrm{~m}^{2} / \mathrm{m}^{3}$, porosity $0.82 \mathrm{~m}^{3} / \mathrm{m}^{3}$, packing density $240 \mathrm{~kg} / \mathrm{m}^{3}$, equivalent diameter $0.0082 \mathrm{~m}$.

The authors will consider the results of experimental studies of a packing material sample in comparison to packing contact devices that are widely used in industries. The 
characteristics of heat and mass transfer packing contact devices have been studied at the experimental a detailed description and capabilities of which are presented in [39, 43].
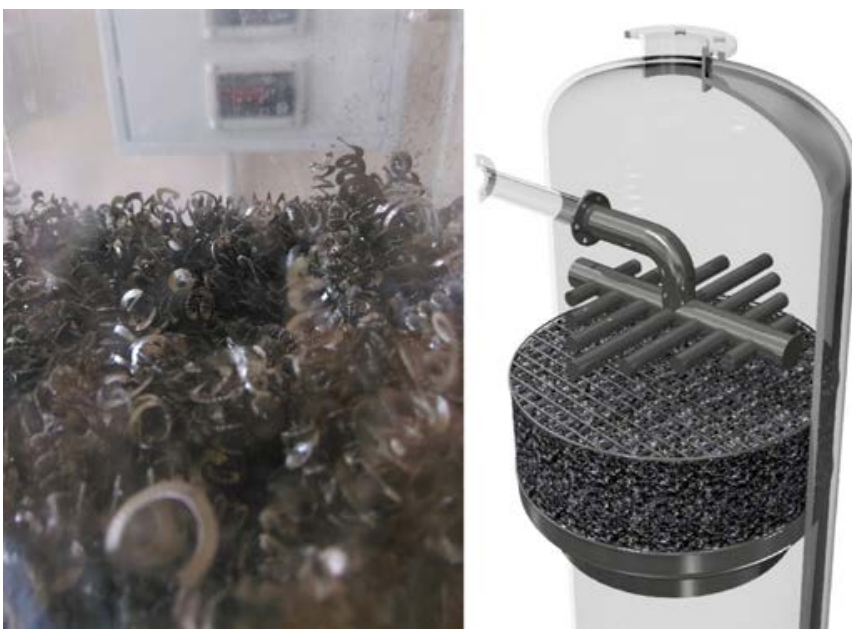

Fig. 1. Photo of packing elements and the scheme of a complete packing cartridge for classifying experimental studies.

The results of experimental studies of packing devices in hydrodynamics of a singlephase filtration flow through the packing layer are shown in Figure 2 (filtration curve 1). Its further processing with the classification criterion dependence $\lambda=f\left(R e_{m}\right)$ described in detail in $[44,45]$ allows predicting the effective industrial use of any packing materials samples. The developed classification technique $\lambda=f\left(R e_{m}\right)$ is especially relevant in the conditions of processing and comparison of large amounts of experimental data and in particular in multiple studies of waste samples from machine-building enterprises (metal shavings). The classification technique $\lambda=f\left(R e_{m}\right)$ graphically presented in Figure 3, after express research of single-phase filtration flows and subsequent data processing, provides industrial use for random packing samples which is especially valuable for adaptation of wastes from machine-building enterprises as contact mass transfer devices.

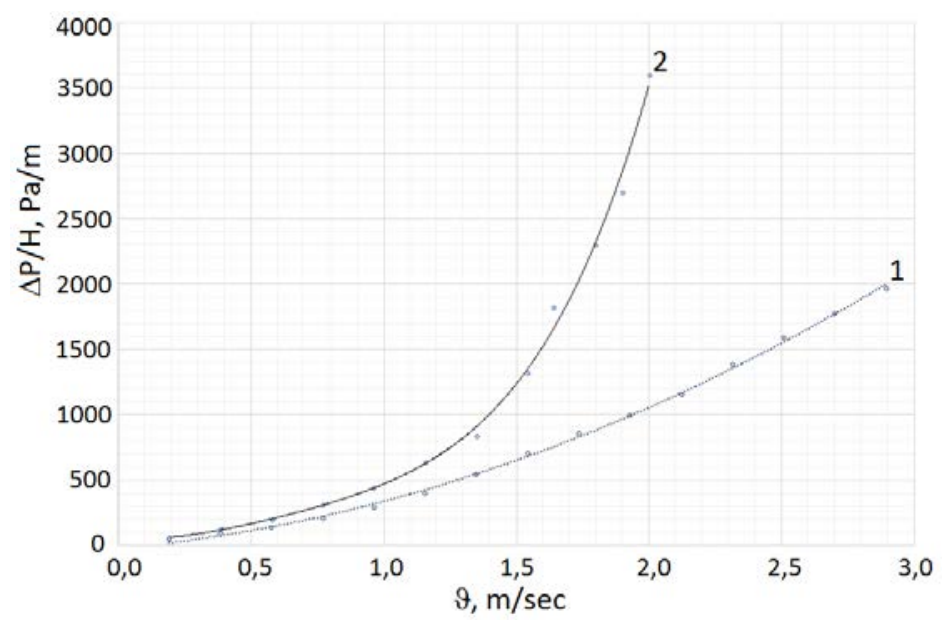

Fig. 2. Filtration curves of single and two-phase flows through the packing layer of the investigated packing material S-Aisi $316 \mathrm{Ti} \varepsilon=0.82 \mathrm{~m}^{3} / \mathrm{m}^{3}: 1$ - dry filtration curve; 2 - irrigated packing material with irrigation density of $1.9 \mathrm{kgW} / \mathrm{m}^{2} \cdot \mathrm{s}$. 
Table 1. Results of processing the experimental data by the classification method $\lambda=f\left(\operatorname{Re}_{m}\right)[44,45]$ for packing material in the form of metalworking wastes from machine-building enterprises (S-Aisi

316Ti material, specific surface $400 \mathrm{~m}^{2} / \mathrm{m}^{3}$, porosity $0.82 \mathrm{~m}^{3} / \mathrm{m}^{3}$, packing density $240 \mathrm{~kg} / \mathrm{m}^{3}$, equivalent diameter $0.0084 \mathrm{~m}$ ).

\begin{tabular}{|c|c|c|c|c|c|}
\hline$\alpha, \mathbf{M}^{-2}$ & $\beta, \mathbf{M}^{-1}$ & $\operatorname{Re}$ & $\lambda$ & $I x_{1}, \mathbf{M}$ & $I x_{2}, \mathbf{m}^{2}$ \\
\hline \multirow{11}{*}{$5.561 \cdot 106$} & \multirow{11}{*}{27.38} & 0.137 & 16.49 & \multirow{11}{*}{0.0365} & \multirow{11}{*}{$4.92 \cdot 10^{-6}$} \\
\hline & & 0.205 & 11.78 & & \\
\hline & & 0.272 & 9.34 & & \\
\hline & & 0.339 & 7.88 & & \\
\hline & & 0.410 & 6.87 & & \\
\hline & & 0.477 & 6.18 & & \\
\hline & & 0.615 & 5.24 & & \\
\hline & & 0.749 & 4.66 & & \\
\hline & & 0.887 & 4.25 & & \\
\hline & & 1.022 & 3.95 & & \\
\hline & & 1.16 & 3.72 & & \\
\hline
\end{tabular}

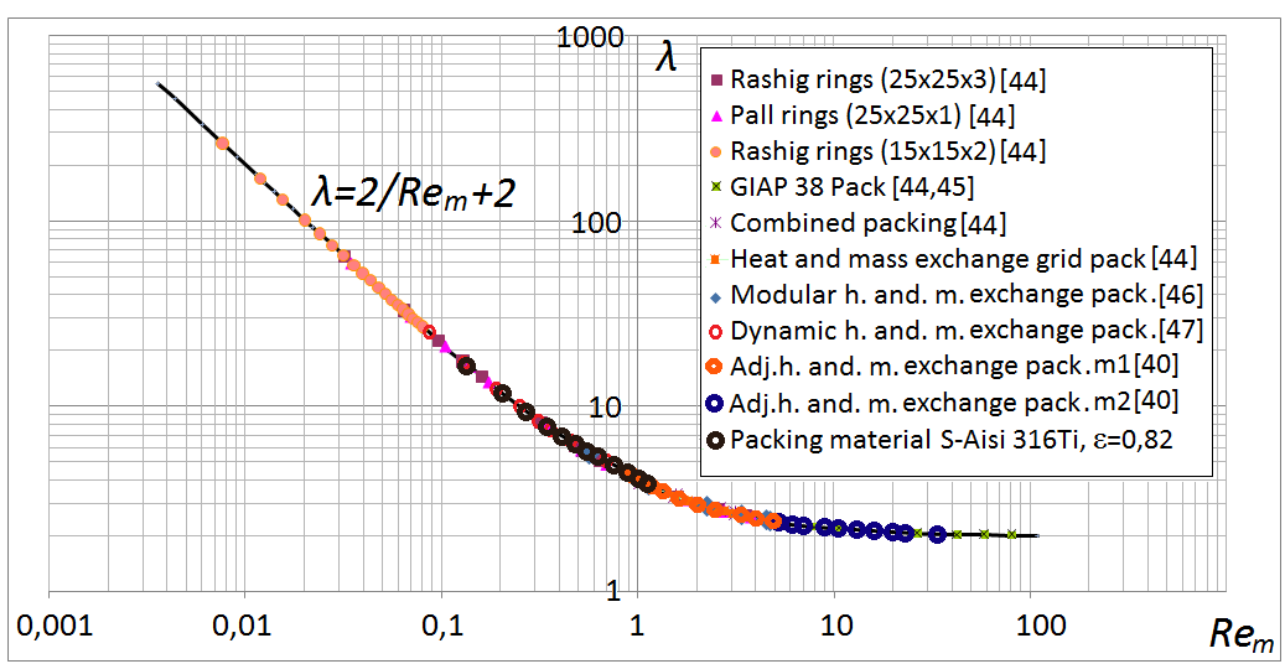

Fig. 3. Classifying criterion dependence $\lambda=f\left(R_{m}\right)$ for adaptation of packing materials according to the range of mass transfer processes.

Based on the analysis of the obtained data (Figure 3) according to the classification criterion dependence $\lambda=f\left(R_{m}\right)$ the studied packing material occupied the operating range by the Reynolds modifying number from 0.137 to 1.16 ; and by the hydraulic resistance coefficient $\lambda$ from 16.49 to 3.72 which corresponds to the absorption process.

At the next stage of experimental studies (Figure 2, filtration curve 2), the hydrodynamic operation modes of the studied packing material were monitored and the retention capacity of the liquid and gas phases (Figure 4) was experimentally determined in comparison to mass exchange packing contact elements which have widely been used in industries; the retention capacity is considered by the authors to be one of the keys to the effective operation of the packing absorber as the accumulating ability of packing devices in the liquid and gas phases contributes to their high-quality mutual mixing and the development of intensive hydrodynamic regimes which in turn increases the productivity and degree of purification of industrial environmental mass transfer devices. The task of mass transfer contact devices focused on the absorption process during selective gas purification is to hold the gas while providing developed contact with the liquid while the gas itself performs a turbulent function creating local or polyemulsification. It is obvious 
that the studied packing material with high efficiency meets the requirements of the absorption process. The experiment has confirmed the ability of the studied packing material to work in developed hydrodynamic modes with the gradual formation of emulsification sources and high turbulization smoothly developing into the emulsification regime throughout the entire volume of the packing with an increase in gas flow rate. These indicators will provide a high degree of purification of gas emissions in environmental processes and allow making a conclusion that this packing material with high efficiency can replace a number of packing devices that have been widely used in industries for the absorption process especially in small absorption columns.

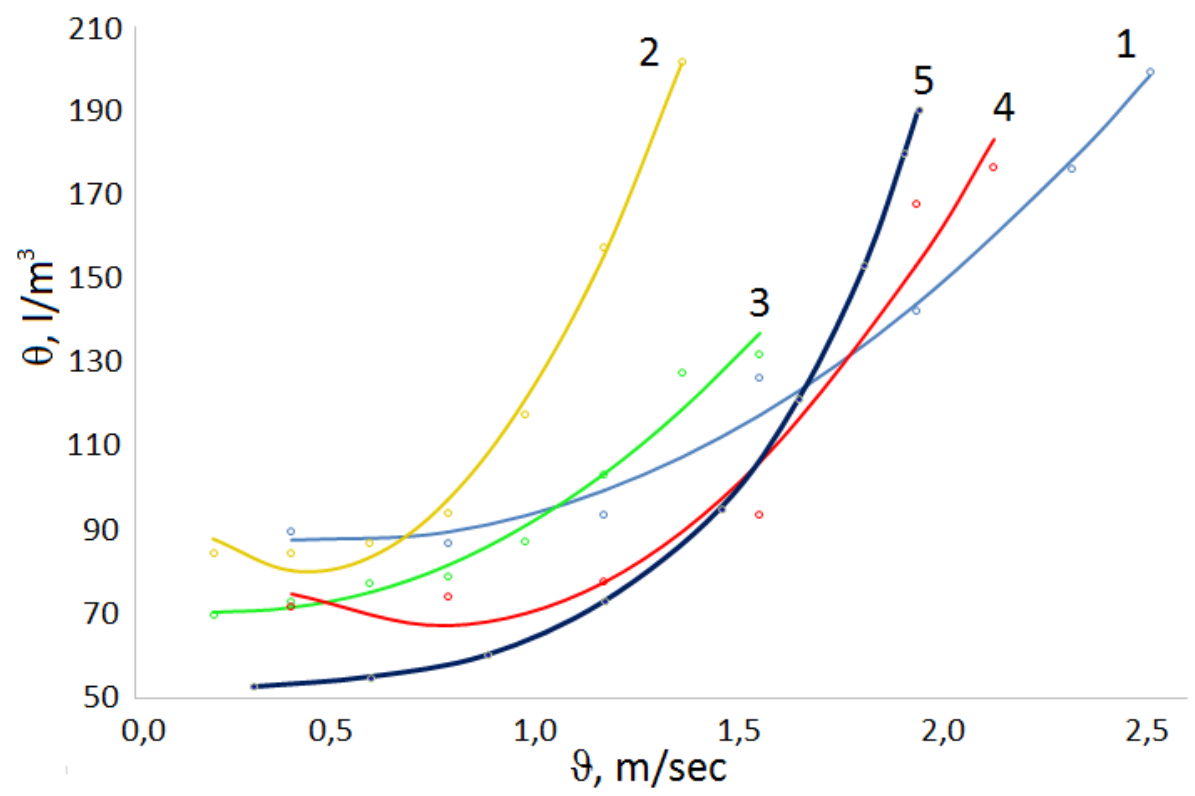

Fig. 4. The holding ability of the packing contact devices in the liquid phase with irrigation density of $1.9 \mathrm{kgW} / \mathrm{m}^{2} \cdot \mathrm{s}$ : 1 - Pall rings 25x25x1mm; 2 - Rashig rings 25x25x3mm; 3 - Raschig rings

25x25x3mm structured; 4 - dynamic mass transfer packing [47], 5 - S-Aisi 316Ti packing material $\varepsilon=0.82 \mathrm{~m}^{3} / \mathrm{m}^{3}$.

As an applied example the authors have given the calculation of an industrial smallsized absorber (Figure 5) for cleaning gas emissions using the studied packing material SAisi316Ti $\varepsilon=0.82$ as a contact device according to the developed methods $[39,48]$. The main technological and geometric parameters of the calculated small-sized sectional absorber for the absorption of acetone vapor from air at atmospheric pressure and a temperature of $20{ }^{\circ} \mathrm{C}$ : the volume fraction of acetone in the initial vapor-air mixture is $9 \%$, the absorbent is pure water, the gas flow rate is $500 \mathrm{~kg} / \mathrm{h}$, the absorption rate is 0.99 , the diameter of the absorption column $0.4 \mathrm{~m}$, the total height of the packing $2.7 \mathrm{~m}$, the height of the section of the mass transfer packing $0.9 \mathrm{~m}$, the number of sections in the absorption column 3. 


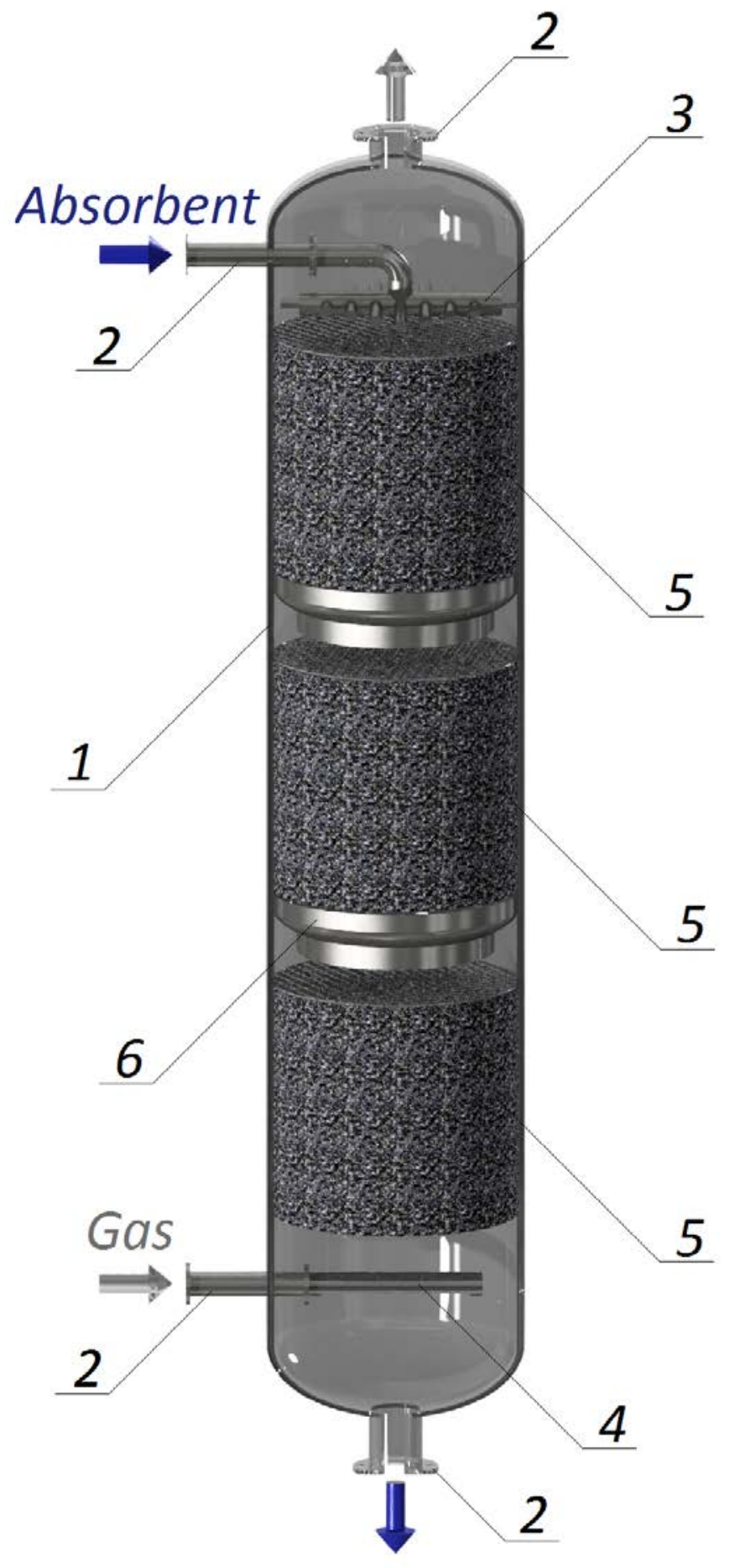

Fig. 5. Industrial small-sized sectional absorption column with the studied mass transfer packing S-Aisi316Ti, $\varepsilon=0.82$ : 1 - body of a small absorption column; 2 - branching pipes for supply and removal of mass transfer products; 3 - liquid distributor; 4 - gas distributor; 5 - packing contact sections; 6 - redistribution devices. 


\section{Conclusions}

Based on the obtained experimental data, the calculated and classifying characteristics, as well as the hydrodynamic regime effects that were observed during the experimental studies the authors can conclude that the use of the studied packing materials for the selective purification of gas emissions in industrial small-sized absorption columns is undoubtedly promising not to mention industrial wastes of machine-building enterprises which appear in very large quantities during metalworking and their use after classification, subsequent adaptation and structural organization in the form of sections of mass transfer devices that is the disposal of industrial wastes.

The packing material studied in this work due to its rigid structure and tight packing has constant structural characteristics and is of very little sensitivity to volumetric deformation. It should be noted that many samples of packing materials have volume elastic properties and can be sensitive to volumetric deformation and control of hydrodynamic regimes [3942] during operation which opens up unique possibilities for manufacturing universal mass transfer contact devices with the possibility of effectively influencing the quality of mass transfer processes, the degree of purification of liquid and gas heterogeneous systems and the concentration of the final products of mass transfer.

\section{References}

1. Sokol B.A., Chermyshov A.K., Baranov D.A., Mass-transfer column packed-type devices (Infokhim, Moscow, 2009).

2. Kagan A.M., Laptev A.G., Pushnov A.S., Farakhov M. I., Contact packings in industrial heat-and-mass transfer apparatuses (Otechestvo, Kazan, 2013).

3. I.N. Madyshev, O.S. Dmitrieva, A.V. Dmitriev, MATEC Web of Conf. 224, 02079 (2018)

4. I.N. Madyshev, O.S. Dmitrieva, A.V. Dmitriev, MATEC Web of Conf. 194, 01036 (2018)

5. K.V. Chizh, A.S. Pushnov, M.G. Berengarten, Chem. and Pet. Eng. 50, 244 (2014)

6. I.N. Madyshev, O.S. Dmitrieva, A.V. Dmitriev, A.N. Nikolaev, Chem. and Pet. Eng. 52, 299 (2016)

7. A.S. Sokolov, A.S. Pushnov, M.V. Shapovalov, Chem. and Pet. Eng. 53, 1 (2017)

8. O.S. Dmitrieva, A.V. Dmitriev, I.N. Madyshev, A.N. Nikolaev, Chem. and Pet. Eng. 53, 130 (2017)

9. A.K. Mitin, N.E. Nikolaikina, A.S. Pushnov, N.A. Zagustina, Chem. and Pet. Eng. 52, 47 (2016)

10. A.V. Dmitriev, O.S. Dmitrieva, I.N. Madyshev, Chem. and Pet. Eng. 53, 430 (2017)

11. M.G. Berengarten, R.I. Bogdanov, V.E. Voronina, Chem. and Pet. Eng. 47, 111 (2011)

12. A.V. Dmitriev, O.S. Dmitrieva, I.N. Madyshev, A.N. Nikolaev, Chem. and Pet. Eng. 53, 501 (2017)

13. A.A. Gorodilov, A.S. Pushnov, M.G. Berengarten, Chem. and Pet. Eng. 50, 84 (2014)

14. I.N. Madyshev, O.S. Dmitrieva, A.V. Dmitriev, A.N. Nikolaev, Chem. and Pet. Eng. 51, 383 (2015)

15. A.E. Ivanov, M.G. Berengarten, M.I. Klyushenkova, Chem. and Pet. Eng. 46, 433 (2010)

16. M.V. Shilin, M.G. Berengarten, A.S. Pushnov, M.I. Klyushenkova, Chem. and Pet. 
Eng. 48, 608 (2013)

17. M.G. Berengarten, A.O. Nevelson, A.S. Pushnov, Chem. and Pet. Eng. 48, 723 (2013)

18. N. Merentsov, A. Persidskiy, V. Lebedev, N. Prokhorenko, A. Golovanchikov, Advances in Intelligent Systems and Computing, 983, 547 (2019)

19. I.N. Madyshev, O.S. Dmitrieva, A.V. Dmitriev, MATEC Web of Conf. 91, 01019 (2017)

20. A.M. Kagan, L.A. Yudina, A.S. Pushnov, Theor. Found. of Chem. Eng. 46, 165-171 (2012)

21. I.N. Madyshev, O.S. Dmitrieva, A.V. Dmitriev, MATEC Web of Conf. 141, 01023 (2017)

22. A.A. Gorodilov, M.G. Berengarten, A.S. Pushnov, Theor. Found. of Chem. Eng. 50, 325 (2016)

23. I.N. Madyshev, O.S. Dmitrieva, A.V. Dmitriev, MATEC Web of Conf 141, 01012 (2017)

24. G.B. Dmitrieva, M.G. Berengarten, A.S. Pushnov, V.Y. Poplavskii, F. Marshik, Chem. and Pet. Eng. 42, 361 (2006)

25. A.B. Golovanchikov, N.A. Merentsov, V.A. Balashov, Chem. and Pet. Eng. 48, 595 (2013)

26. A.S. Pushnov, M.G. Berengarten, M.G. Lagutkin, A.S. Sokolov, A.I. Shustikov, Chem. and Pet. Eng. 44, 307 (2008)

27. I.N. Madyshev, O.S. Dmitrieva, A.V. Dmitriev, MATEC Web of Conf. 194, 01013 (2018)

28. A.A. Gorodilov, M.G. Berengarten, A.S. Pushnov, Theor. Found. of Chem. Eng. 50, 422 (2016)

29. N.A. Merentsov, V.N. Lebedev, A.V. Persidskiy, V.A. Balashov, IOP Conf. Ser.: Earth and Environmental Science 288, 012106 (2019)

30. A.S. Pushnov, M.G. Berengarten, A.M. Kagan, A.S. Ryabushenko, A.V. Stremyakov, Chem. and Pet. Eng. 43, 575 (2007)

31. K.B. Komissarov, A.V. Fil', V.A. Finochenko, Chem. and Pet. Eng. 53, 814 (2018)

32. G.V. Kuznetsov, D.V. Feoktistov, E.G. Orlova, S. Y. Misyura, V.S. Morozov, A.G. Islamova, Int. J. Heat Mass Transfer 126, 161 (2018)

33. K. Ponomarev, E. Orlova, D. Feoktistov, EPJ Web Conf. 110, 01060 (2016)

34. A. Golovanchikov, N. Merentsov, Advances in Intelligent Systems and Computing 983, 645 (2019)

35. V. Maksimov, T. Sharifulin, L. Zhidkova, K. Eloyan, EPJ Web Conf. 159, 00033 (2017)

36. M. Shilyaev, E. Khromova, A. Bogomolov, MATEC Web of Conf. 115, 08006 (2017)

37. A.E. Ivanov, M.G. Berengarten, M.I. Klyushenkova, Chem. and Pet. Eng. 45, 526 (2009)

38. O.S. Dmitrieva, A.V. Dmitriev, I.N. Madyshev, L.V. Kruglov, MATEC Web of Conf. 129, 06010 (2017)

39. N. Merentsov, A. Persidskiy, V. Lebedev, M. Topilin, A. Golovanchikov Advances in Intelligent Systems and Computing 983, 560 (2019)

40. A.V. Persidskiy, N.A. Merentsov, V.N. Lebedev, A.B. Golovanchikov, IOP Conf. Ser.: Earth and Environmental Science 288, 012110 (2019) 
41. N. Merentsov, A. Persidskiy, V. Lebedev, Materials Today: Proceedings (2019) https://doi.org/10.1016/j.matpr.2019.07.037 (to be published)

42. N. Merentsov, A. Persidskiy, M. Topilin, Materials Today: Proceedings (2019) https://doi.org/10.1016/j.matpr.2019.07.039 (to be published)

43. N.A. Merentsov, A.V. Persidskiy, M.V. Topilin, V.N. Lebedev, V.A. Balashov, A.B. Golovanchikov, Journal of Phys.: Conf. Ser. 1278, 012024 (2019)

44. N.A. Merentsov, V.A. Balashov, D.Y. Bunin, V.N. Lebedev, A.V. Persidskiy, M.V. Topilin, MATEC Web of Conf. 243, 5 (2018)

45. A.B. Golovanchikov, V.A. Balashov, N.A. Merentsov, Chem. and Pet. Eng. 53, 10 (2017)

46. N.A. Merentsov, V.N. Lebedev, A.B. Golovanchikov, V.A. Balashov, E.E. Nefed'Eva, IOP Conf. Ser: Earth and Environmental Science 115 (2018)

47. A.B. Golovanchikov, N.A. Merentsov, M.V. Topilin, A.V. Persidskiy, IOP Conf. Ser.: Earth and Environmental Science 288, 012089 (2019)

48. A. Golovanchikov, N. Merentsov, Advances in Intelligent Systems and Computing 983, 635 (2019) 